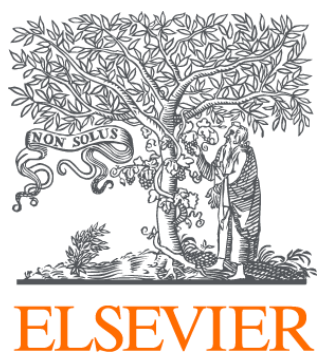

Since January 2020 Elsevier has created a COVID-19 resource centre with free information in English and Mandarin on the novel coronavirus COVID-

19. The COVID-19 resource centre is hosted on Elsevier Connect, the company's public news and information website.

Elsevier hereby grants permission to make all its COVID-19-related research that is available on the COVID-19 resource centre - including this research content - immediately available in PubMed Central and other publicly funded repositories, such as the WHO COVID database with rights for unrestricted research re-use and analyses in any form or by any means with acknowledgement of the original source. These permissions are granted for free by Elsevier for as long as the COVID-19 resource centre remains active. 


\title{
Radiative effects of reduced aerosol emissions during the COVID-19 pandemic and the future recovery
}

\author{
Stephanie Fiedler ${ }^{a, b, *}$, Klaus Wyser ${ }^{c}$, Joeri Rogelj ${ }^{\mathrm{d}, \mathrm{e}}$, Twan van Noije ${ }^{\mathrm{f}}$ \\ ${ }^{a}$ University of Cologne, Institute of Geophysics and Meteorology, Cologne, Germany \\ ${ }^{\mathrm{b}}$ Hans-Ertel-Centre for Weather Research, Climate Monitoring and Diagnostics, Bonn/Cologne, Germany \\ ${ }^{\mathrm{c}}$ Rossby Centre, Swedish Meteorological and Hydrological Institute, Sweden \\ ${ }^{\mathrm{d}}$ Grantham Institute, Imperial College London, United Kingdom \\ ${ }^{\mathrm{e}}$ International Institute for Applied Systems Analysis, Laxenburg, Austria \\ ${ }^{\mathrm{f}}$ Royal Netherlands Meteorological Institute, De Bilt, Netherlands
}

\section{A R T I C L E I N F O}

\section{Keywords:}

Anthropogenic aerosols

Radiative forcing

COVID-19 pandemic

Scenarios

CMIP6

CovidMIP

\begin{abstract}
A B S T R A C T
The pandemic in 2020 caused an abrupt change in the emission of anthropogenic aerosols and their precursors. We estimate the associated change in the aerosol radiative forcing at the top of the atmosphere and the surface. To that end, we perform new simulations with the CMIP6 global climate model EC-Earth3. The simulations use the here newly created data for the anthropogenic aerosol optical properties and an associated effect on clouds from the simple plumes parameterization (MACv2-SP), based on revised $\mathrm{SO}_{2}$ and $\mathrm{NH}_{3}$ emission scenarios. Our results highlight the small impact of the pandemic on the global aerosol radiative forcing in 2020 compared to the CMIP6 scenario SSP2-4.5 of the order of $+0.04 \mathrm{Wm}^{-2}$, which is small compared to the natural year-to-year variability in the radiation budget. Natural variability also limits the ability to detect a meaningful regional difference in the anthropogenic aerosol radiative effects. We identify the best chances to find a significant change in radiation at the surface during cloud-free conditions for regions that were strongly polluted in the past years. The post-pandemic recovery scenarios indicate a spread in the aerosol forcing of -0.68 to $-0.38 \mathrm{Wm}^{-2}$ for 2050 relative to the pre-industrial, which translates to a difference of +0.05 to $-0.25 \mathrm{Wm}^{-2}$ compared to the 2050 baseline from SSP2-4.5. This spread falls within the present-day uncertainty in aerosol radiative forcing and the CMIP6 spread in aerosol forcing at the end of the 21st century. We release the new MACv2-SP data for studies on the climate response to the pandemic and the recovery scenarios. Our 2050 forcing estimates suggest that sustained aerosol emission reductions during the post-pandemic recovery cause a stronger climate response than in 2020 , i.e., there is a delayed influence of the pandemic on climate.
\end{abstract}

\section{Introduction}

The aerosol burden in 2020 is affected by reduced emissions of anthropogenic aerosols and their precursors associated with the global COVID-19 pandemic. Many countries have witnessed a reduction in socio-economic activities and lockdowns. The associated decline in traffic and industrial productivity have led to marked regional reductions in atmospheric pollution improving the air quality (e.g., van Heerwaarden et al., 2021; Ranjan et al., 2020). Fig. 1 illustrates the observed anomaly in the mid-visible aerosol optical depth, $\tau^{\prime}$, for northern hemisphere spring in 2020, calculated as the difference against the 20-year spring climatology from NASA's MODIS satellite product MOD08_M3 v6.1 (Acker and Leptoukh, 2007; Platnick et al., 2015), assessed in more detail by Sanap (2021). Pronounced negative $\tau^{\prime}$ in spring 2020 are identified for Eastern and Southern Asia as well as the Northwest Pacific. Even Europe and North America, where the mean anthropogenic aerosol burden is relatively small, have seen less aerosols during spring 2020. Albeit an influence of negative regional trends in anthropogenic aerosol emissions due to legislation (e.g., Sun et al., 2018; Chu et al., 2020; Cherian and Quaas, 2020), and variability in aerosol emissions from natural sources (e.g., Riemer et al., 2021; Song et al., 2021), the pandemic is a clear contributor to $\tau^{\prime}$, consistent with other findings. For instance, the pandemic restrictions in most of the European countries occurs in parallel with exceptionally blue skies and new extremes in surface irradiance (van Heerwaarden et al., 2021). Improved air quality associated with COVID-19 lockdowns were also documented

\footnotetext{
* Corresponding author at: University of Cologne, Institute of Geophysics and Meteorology, Cologne, Germany.

E-mail address: stephanie.fiedler@uni-koeln.de (S. Fiedler).
} 

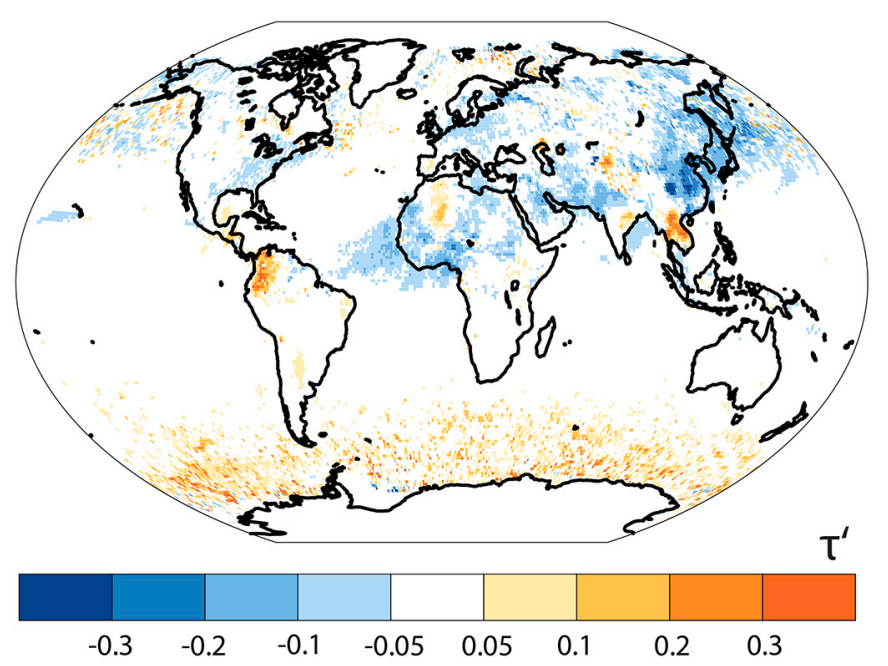

Fig. 1. Observed anomaly in aerosol optical depth for northern hemisphere spring 2020. Shown is the anomaly in the aerosol optical depth $\left(\tau^{\prime}\right)$ at $550 \mathrm{~nm}$ for March-May 2020 against the climatology of the same months for 2000-2020 from MODIS.

for India (Srivastava et al., 2021; Zhang et al., 2021), Iran (Broomandi et al., 2020), and the United States (Berman and Ebisu, 2020).

The emission reductions due to the COVID-19 pandemic are thought to potentially influence climate (e.g., Forster et al., 2020a; Gettelman et al., 2020; Yang et al., 2020), but the emission reductions are not considered in the contemporary climate simulations of the Coupled Model Intercomparison Project phase 6 (CMIP6, Eyring et al., 2016), used for assessing climate changes by the Intergovernmental Panel on Climate Change (IPCC). The construction of the CMIP6 scenarios of anthropogenic emissions has therefore been revisited (Forster et al., 2020b). Based on the new emission data, the scientific community plans to investigate the co-occurrence of climate anomalies and the COVID-19 impacts on global air quality. To this end, a new climate model inter-comparison project with the revised emission scenarios for 2015-2050 has been proposed (CovidMIP, Lamboll et al., 2021) under the umbrella of the Detection and Attribution Model Intercomparison Project (DAMIP, Gillett et al., 2016) endorsed by CMIP6. Nine CMIP6 models in the sixth assessment report of the IPCC (IPCC, 2021) use the simple plumes aerosol parameterization MACv2-SP (Fiedler et al., 2017; Stevens et al., 2017). Some of them like EC-Earth3 and MPI-ESM1.2 participate in CovidMIP and therefore need MACv2-SP input data consistent with the new emission data of CovidMIP. We here derive these new input data for MACv2-SP and provide it for use in climate studies.

The aim of the present study is to estimate the impact of the COVID19 pandemic on the radiative forcing of anthropogenic aerosols for the pandemic year 2020 and the new recovery scenarios in 2050. A first estimate of the radiative forcing associated with aerosol-radiation interaction from a complex aerosol-climate model has been made for spring 2020 (Weber et al., 2020). Here, we provide the first estimates of the effective radiative forcing for the entire years 2020 and 2050 from MACv2-SP that account for both aerosol-radiation and aerosol-cloud interactions as well as the large impact of the variability in rapid adjustments. To this end, we derive and describe the new MACv2-SP data for the anthropogenic aerosol optical properties and an associated effect on clouds for 2015-2050 from the revised aerosol emissions (Forster et al., 2020b). These emission data cover different recovery pathways after the pandemic ranging from fossil-fuel based to green developments into the future. We use the here newly constructed MACv2-SP data in the CMIP6 model EC-Earth3 (Döscher et al., 2021), which uses MACv2-SP to represent anthropogenic aerosols. EC-Earth3 simulates aerosol-radiation and aerosol-cloud interactions including both the
Twomey effect and cloud adjustments with MACv2-SP. We perform new atmosphere-only experiments with EC-Earth3 and estimate the effective radiative forcing (ERF) of the anthropogenic aerosols in 2020 and 2050 at the top of the atmosphere and the surface. Details of our methods are given in Section 2, followed by our results in Section 3, and a discussion with conclusions in Section 4.

\section{Methods}

\subsection{Emissions of $\mathrm{SO}_{2}$ and $\mathrm{NH}_{3}$}

Forster et al. (2020b) developed five new scenarios to explore the impact of the COVID-19 pandemic on current and future anthropogenic emissions. These scenarios are:

- A baseline scenario (base) without any impact of the COVID-19 pandemic and the measures to contain it;

- A two-year-blip scenario ( $b l p$ ) that assumes emissions return to the baseline scenario after a two-year reduction in emissions due to temporary societal lockdowns and disruptions;

- A fossil-fuel recovery scenario ( $f f$ ) that assumes the recovery from the COVID-19 economic downturn preferentially supports polluting fossil-fuel-based economic sectors;

- A moderate and strong green recovery scenario (called $m g$ and $s g$, respectively) that assume different levels of preferential stimulus of green sectors during the recovery from COVID-19 (e.g., see Andrijevic et al., 2020) that would lead to limiting global mean temperature increase relative to preindustrial levels to well below $2{ }^{\circ} \mathrm{C}$ and to $1.5^{\circ} \mathrm{C}$, respectively (Forster et al., 2020b).

The near-term evolution of $\mathrm{SO}_{2}$ and $\mathrm{NH}_{3}$ during the COVID-19 lockdown period uses the activity scaling method of Forster et al. (2020b). For the extensions beyond the COVID-19 lockdown period and until 2050, the large-scale global relationships between greenhouse gases, aerosols and aerosol precursors as found in detailed emissions scenarios derived with integrated assessment models is used (Lamboll et al., 2020b). That is the emission data produced with the python package Silicone v1.0.0 for inferring emission data of multiple chemical species. It allows to fill missing data of one species based on reports on emissions of other species, e.g., $\mathrm{N}_{2} \mathrm{O}$ projections for a given $\mathrm{CO}_{2}$ emission using the relationship of $\mathrm{N}_{2} \mathrm{O}$ and $\mathrm{CO}_{2}$ from another scenario. Emissions evolutions of $\mathrm{SO}_{2}$ and $\mathrm{NH}_{3}$ compatible with each of the above scenarios have been estimated, based on the relationships found in the scenario ensemble compiled and assessed as part of the Intergovernmental Panel on Climate Change's (IPCC) Special Report on Global Warming of $1.5^{\circ} \mathrm{C}$ (Rogelj et al., 2018; Huppmann et al., 2018). The dataset defines eight emission sectors, namely agriculture, energy, waste, transportation, international shipping, and solvent production and application as well as industrial, residential, and commercial sectors plus a remaining fraction classified as other.

For illustrating the difference in emissions due to the pandemic in 2020, we show the difference in the emission sum of $\mathrm{SO}_{2}$ and $\mathrm{NH}_{3}$ emissions from all sectors for 2020 for the $b l p$ scenario against base (Fig. 2). The reduction in the emissions of $\mathrm{SO}_{2}$ plus $\mathrm{NH}_{3}$ due to the pandemic is globally visible, with particularly pronounced impacts on the emissions in Asia and the Pacific coast of South America measured by the absolute differences (Fig. 2a). Emission changes for 2020 associated with the pandemic translate to regional differences by up to $-37 \%$ at the Western coast of South America and mostly $-14 \%$ over the oceans relative to base, while reductions in Asian countries are at the order of a few percent (Fig. 2b). In the global area-weighted mean, the reduction of the $\mathrm{SO}_{2}$ plus $\mathrm{NH}_{3}$ emission sum for 2020 is $-11 \%$ in $b l p$ against base. The reduction in $\mathrm{SO}_{2}$ emissions $(-14 \%)$ is slightly stronger than for $\mathrm{NH}_{3}$ emissions $(-10 \%)$. The percentage reductions in $\mathrm{SO}_{2}$ and $\mathrm{NH}_{3}$ emissions per sector are similar. Strongest reductions in the 2020 emission sums are associated with transportation $(-20 \%)$, international 

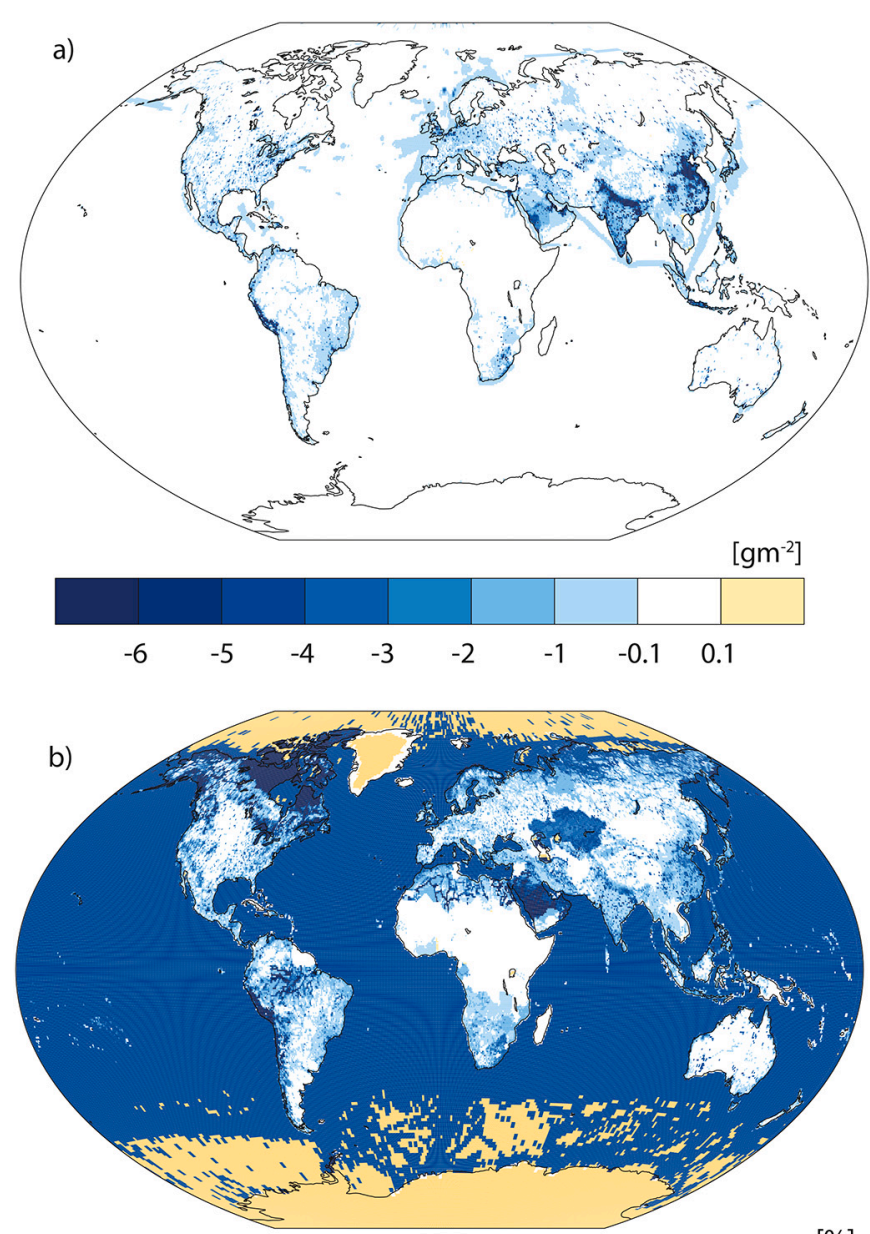

[\%]

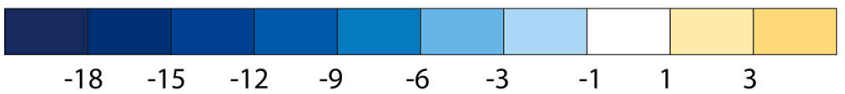

Fig. 2. Aerosol emission difference for 2020 due to pandemic. Shown are the reductions in the emission sum of $\mathrm{SO}_{2}$ and $\mathrm{NH}_{3}$ for the blp scenario against base (a) as absolute difference in $\mathrm{gm}^{-2}$ per year and (b) as percentage change per year relative to base. All values are based on sums for the year 2020 over all emission sectors.

shipping (-14\%) and industrial sources $(-14 \%)$ in blp relative to base. There are no differences for agriculture, waste, and solvents production and applications. Emissions of $\mathrm{SO}_{2}$ and $\mathrm{NH}_{3}$ are used to construct the MACv2-SP data in the next Section.

\subsection{Anthropogenic aerosol parameterization}

We use the emissions of $\mathrm{SO}_{2}$ and $\mathrm{NH}_{3}$ from Forster et al. (2020b) to create the new input data for the novel simple-plumes parameterization MACv2-SP (Fiedler et al., 2017; Stevens et al., 2017) in use for representing anthropogenic aerosol effects in climate models of CMIP6 (e.g., Fiedler et al., 2019a; Mauritsen et al., 2019). MACv2-SP prescribes month-to-month and year-to-year changes of the three dimensional fields of anthropogenic aerosol optical properties and associated effects on clouds. Temporal changes from 1850 to 2100 have been derived by scaling the anthropogenic aerosol optical depth of 2005 with the CMIP6 emission amounts of $\mathrm{SO}_{2}$ and $\mathrm{NH}_{3}$ (Stevens et al., 2017; Fiedler et al., 2019b). Emissions of $\mathrm{SO}_{2}$ and $\mathrm{NH}_{3}$ are chosen for consistency with earlier data constructions for MACv2-SP, motivated by the assumption that temporal changes in other anthropogenic aerosol species correlate with them (Stevens et al., 2017), e.g., $\mathrm{NO}_{x}$. Large-scale co-variability in $\mathrm{NO}_{x}, \mathrm{SO}_{2}$, and $\mathrm{NH}_{3}$ is for instance also found for the emission data used here (Forster et al., 2020a). Evaluating the MACv2-SP approach against the aerosol optical depth from a complex aerosol-climate model indicates similar regional scaling behaviours (Fiedler et al., 2019b). Moreover, our MACv2-SP data in CovidMIP models generate results that fall within the spread from aerosol-climate model simulations with more complex aerosol treatments (Jones et al., 2021). A complete technical description of MACv2-SP is given by Stevens et al. (2017). Again previous data for MACv2-SP did not account for the effect of the pandemic on anthropogenic emissions. We therefore create here new MACv2-SP input data, based on the emission data sets for 2015-2050 accounting for the COVID-19 pandemic and the four recovery scenarios from Forster et al. (2020b).

For creating the new MACv2-SP data, we scale the anthropogenic aerosol optical depth and the effect on clouds from 2005 to other years by multiplying scaling factors in the centre of the nine plumes, marked in Fig. 3a. Mathematical functions in MACv2-SP use the values in the plume centers to create the three dimensional distribution of the aerosol extinction. As an example, Fig. 3 shows the maps of the mid-visible anthropogenic aerosol optical depth in 2050 from MACv2-SP for three scenarios that we derive here. Technically, we create annual scaling factors for each plume center and each year to be represented in MACv2SP.

Our method for constructing the scaling factors for MACv2-SP is similar to the method for the CMIP6 scenarios (Fiedler et al., 2019b). The anthropogenic aerosol optical depth $\tau_{i}$ in each plume center $i=1$, .., 9 is scaled with the emission scaling factor $E_{i}$ for the years $t$ with:

$\tau_{i}(t)=E_{i}(t) \tau_{i}(2005)$

We use $\tau_{i}$ (2005) at $550 \mathrm{~nm}$ from Stevens et al. (2017). The scaling factors $E_{i}(t)$ are constructed from the anthropogenic emission $\varepsilon_{i k}$ of the species $k$. These are the gridded emission data for $\mathrm{SO}_{2}$ and $\mathrm{NH}_{3}$ from the emission data version 4 (Forster et al., 2020b). These emission data are provided on a longitude-latitude grid with a resolution of $0.5^{\circ} \times 0.5^{\circ}$ (Fig. 2). The calculation of $E_{i}(t)$ follows Fiedler et al. (2019a):

$E_{i}(t)=\frac{\sum_{k=1,2} w_{k}\left[\varepsilon_{\mathrm{ik}}(t)-\varepsilon_{\mathrm{ik}}(1850)\right]}{\sum_{k=1,2} w_{k}\left[\varepsilon_{\mathrm{ik}}(2005)-\varepsilon_{\mathrm{ik}}(1850)\right]}$

The emissions of 1850 and 2005 are taken from the CMIP6 historical emission data. We consider emissions from all anthropogenic sectors provided by Forster et al. (2020b), and include open burning emissions from the CMIP6 scenario SSP2-4.5. SSP2-4.5 is the baseline for the experiments to be carried out in CovidMIP (Lamboll et al., 2021). The anthropogenic emissions $\varepsilon_{i k}$ are integrated values over the $10 \times 10$ grid boxes surrounding the plume center. The weights $w_{k}$ for the two species are $w_{1}=0.645$ for $\mathrm{SO}_{2}$ and $w_{2}=0.355$ for $\mathrm{NH}_{3}$, representing the forcing ratio of sulphate against ammonium for present day (Stevens et al., 2017).

Fig. 4 shows examples of the scaling factors for each of the nine aerosol plume centers $i$. Contrasting the baseline against the two-yearblip data illustrates the reduction of $E_{i}$ for 2020-2021. The reduction for $E_{i}$ is particularly strong for the plumes over India and South America. These are consistent with emission reductions in anthropogenic aerosols and their precursors in many regions across Asia for 2020 (Fig. 2). In South America, the reductions are particularly strong near the Pacific coast. Comparably smaller changes are seen in Europe, Africa, and North America, consistent with relatively less emission reductions.

MACv2-SP typically uses one $E_{i}(t)$ per decade with linear interpolation in between. This is the same here, except that we also construct the scaling factors for the individual years around 2020 for consistency with the new emission data considering the pandemic. We note that the observed small-scale structures in the aerosol burden, e.g., like in local observations, cannot be created with MACv2-SP owing to the design and purpose of this parameterization (Stevens et al., 2017). MACv2-SP is a fast and flexible parameterization of anthropogenic aerosols to represent 

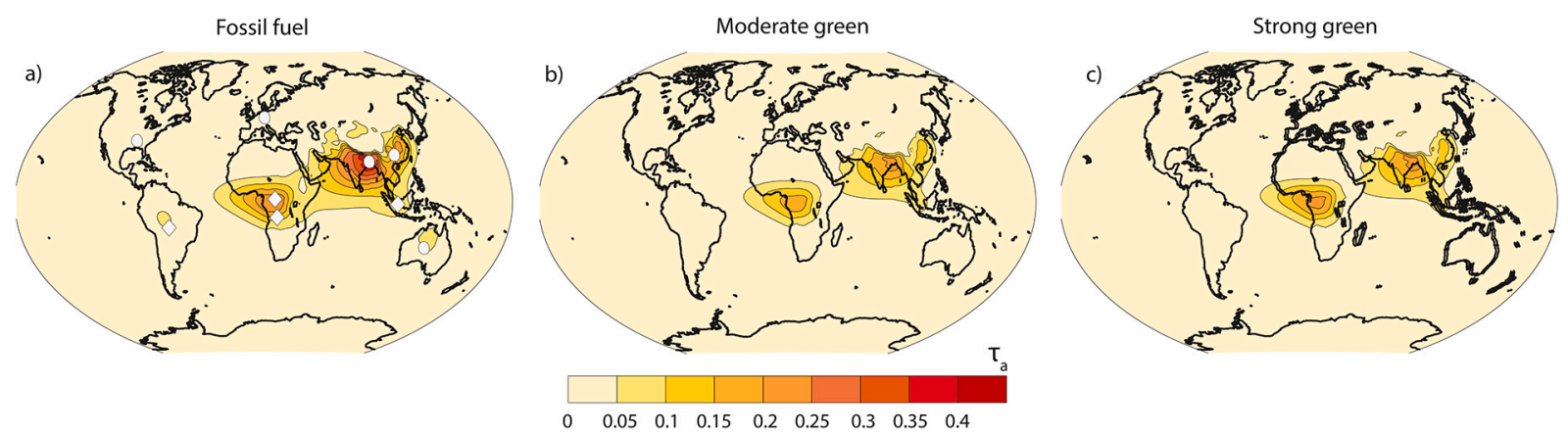

Fig. 3. MACv2-SP $\tau_{a}$ in 2050. Shown is the annual mean in anthropogenic aerosol optical depth $\left(\tau_{a}\right)$ at $550 \mathrm{~nm}$ for the (a) fossil-fuel based, (b) moderate green, and (c) strong green scenario. Grey symbols mark the centers of the aerosol plumes associated with industrial pollution (circles) and emissions from both industry and biomass burning (rectangles).

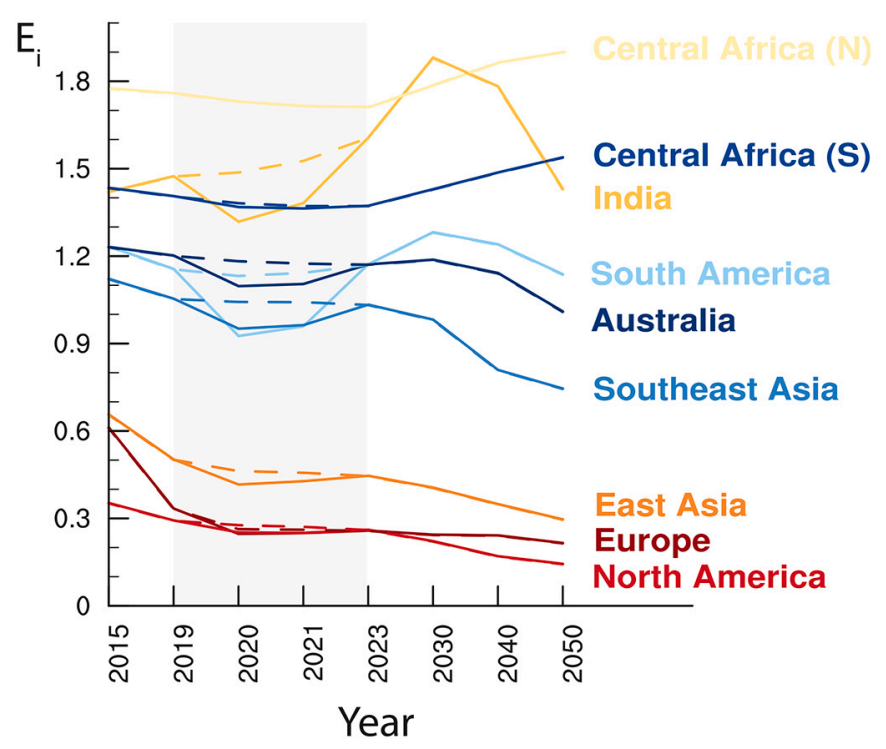

Fig. 4. Example of the scaling factors for the aerosol optical depth in the centre of the aerosol plumes for two scenarios. Shown are the annual scaling factors for the color-coded plumes calculated from the (solid) baseline and (dashed) two-year-blip emissions for the years provided in the data. The pandemic period 2019-2023 is marked with grey shading.

their effects on climate. As such results from using these individual years in later studies should be interpreted as estimates for the large-scale influence and not as local constraints of the forcing for individual years.

Aerosol absorption is prescribed with the single scattering albedo of $\omega_{0}=0.93$ for industrial plumes and $\omega_{0}=0.87$ for plumes additionally affected by biomass burning, marked in Fig. 3a, accounting for regional differences in the aerosol mixture. The asymmetry parameter, $\gamma=0.63$, is constant. MACv2-SP uses the Angstrom exponent $\alpha=2$ to interpolate the aerosol optical properties for different wavelengths.

Additionally to the aerosol optical properties, MACv2-SP prescribes aerosol effects on the cloud droplet number concentrations $N$. The latter is induced with the prefactor $\eta_{N}$ to be multiplied with $N$ in the host model:

$\eta_{N}=1+\frac{\mathrm{dN}}{N}=\frac{\ln \left[1000\left(\tau_{a}(\varphi, \lambda, t)+\tau_{b}(\varphi, \lambda, t)\right)+1\right]}{\ln \left[1000 \tau_{b}(\varphi, \lambda, t)+1\right]}$

The background aerosol optical depth $\left(\tau_{b}\right)$ is a simplified representation that follows the plume structure for $\tau_{a}$ to parameterize the aerosol effect on clouds. Host models can multiply $\eta_{N}$ with $N$ in the radiation transfer calculation to induce a Twomey effect only, e.g., in MPI-ESM1.2, or in the cloud microphysics to allow further rapid adjustments of clouds, e. g., in EC-Earth3 used here. Additional documentation of MACv2-SP and details on the application in climate studies is given elsewhere (e.g., Fiedler et al., 2017, 2019a; Stevens et al., 2017).

The new MACv2-SP input data are provided as supplementary material for use in climate studies, e.g., in CovidMIP (Lamboll et al., 2021). It covers the baseline and scenarios that assume recoveries after the COVID-19 pandemic that intensify the use of fossil fuels, follow a moderate or strong green pathway, and return to a business as usual pathway after the assumed two-year interruption by the pandemic in 2020 and 2021.

\subsection{Model experiment design}

We estimate the ERF of the anthropogenic aerosol reduction in 2020 and the ERF spread associated with the recovery scenarios in 2050 from the new data. To this end, we perform atmosphere-only simulations with EC-Earth3 and compute the ERF of the anthropogenic aerosols at the top of the atmosphere and the surface, i.e., the instantaneous radiative effects plus the rapid adjustments in the atmosphere.

EC-Earth3 is an Earth system model participating in CMIP6 (Döscher et al., 2021). EC-Earth consists of an atmosphere and land surface model adapted from cycle $36 \mathrm{r} 4$ of the European Centre for Medium-Range Weather Forecasts (ECMWF) Integrated Forecasting System (IFS), documented online (ECMWF, 2010a,b, last accessed 4 Jan 2021), coupled to the physical ocean and sea-ice model from NEMO3.6 (Madec and the NEMO team, 2016), and a river runoff model based on CaMa-Flood v3.6.2 (Yamazaki et al., 2013). The model grid chosen here has a horizontal resolution of about $80 \mathrm{~km}$ and 91 vertical levels up to $0.01 \mathrm{hPa}$.

The implementation of MACv2-SP in EC-Earth3 is such that the model accounts for aerosol-radiation interactions and aerosol-cloud interactions, including Twomey and cloud lifetime effects (e.g., Fiedler et al., 2019a). Natural tropospheric aerosols are prescribed with a monthly climatology of pre-industrial aerosol optical properties and concentrations representative for the year 1850. This climatology was produced in an offline simulation of TM5, the atmospheric chemistry and aerosol component of EC-Earth3-AerChem (van Noije et al., 2021). TM5 includes contributions from sulphate, black carbon, primary and secondary organics, sea salt, mineral dust, ammonium, nitrate and methane sulfonic acid. Shortwave radiative effects of tropospheric aerosols are determined by the combined pre-industrial and anthropogenic contributions to the aerosol extinction, absorption (single-scattering albedo), and asymmetry factor; their longwave radiative effects are calculated based on the pre-industrial mass concentrations of different aerosol species. Cloud droplet number concentrations are calculated from the pre-industrial aerosol number and mass concentrations following the activation scheme from Abdul-Razzak and Ghan (2000), and modified by the anthropogenic enhancement factor provided by MACv2-SP. Both the cloud droplet effective radius and the rate 
of autoconversion of cloud liquid to rain depend on the cloud droplet number concentration (van Noije et al., 2021). Consequently, the anthropogenic aerosol forcing in EC-Earth3 includes a contribution from the cloud lifetime or second indirect effect.

Our simulations use annually repeating aerosol optical properties and associated effects on clouds for the years 2020 and 2050. We run experiment with the same setup except for these changes in the anthropogenic aerosols:

- base: new MACv2-SP properties from the baseline for the year 2020 (2020-base) and 2050 (2050-base).

- 2020-blp: new MACv2-SP properties from the two-year-blip for 2020,

- 2050: new MACv2-SP properties for 2050 from the recovery scenarios that are either primarily fossil-fuel based (2050-ff), moderate (2050-mg) or strong green (2050-sg)

- pi: without anthropogenic aerosol effects for calculating the ERF in 2020 and 2050 relative to the pre-industrial.

Our setup of these experiments follows Wyser et al. (2020). These are pre-industrial atmosphere-only experiments, as typical for effective radiative forcing calculations from contemporary climate model experiments (Pincus et al., 2016; Fiedler et al., 2019a; Smith et al., 2020). We prescribe annually repeating pre-industrial boundary conditions like for a piClim-control experiment in the Radiative Forcing Model Inter-comparison project (RFMIP, Pincus et al., 2016), i.e., a monthly climatology for sea-surface temperatures and sea ice, here calculated from 120 years of the model's pre-industrial control experiment for CMIP6. All our experiments are run for 55 years. The first five simulation years are discarded in our analyses. We compute 50-year averages for ERF, substantially reducing the impact of natural year-to-year variability on the estimate (Fiedler et al., 2019a).

\section{Results}

\subsection{Annual means of $\tau_{a}$ and $\eta_{N}$}

We show the global annual means of the anthropogenic aerosol optical depth $\left(\overline{\tau_{a}}\right)$ and the prefactor for inducing aerosol effects on clouds $\left(\overline{\eta_{N}}\right)$ from MACv2-SP in Fig. 5. Note that we here show results from the new MACv2-SP data derived and provided in the framework of this study, but we only use the MACv2-SP data for 2020 and 2050 in timeslice simulations with EC-Earth3 later. We find that both $\overline{\tau_{a}}$ and $\overline{\eta_{N}}$ clearly reduce during the pandemic, e.g., by 0.002 for 2020 compared to the baseline and by 0.005 compared to 2005 . These translate to a reduction by about $10 \%$ and $25 \%$ for the global $\overline{\tau_{a}}$ in 2020 and 2050 . The associated effect on $\overline{\eta_{N}}$ is consistent with the change in $\overline{\tau_{a}}$, with a reduction of $\overline{\eta_{N}}$ by 0.004 compared to baseline and 0.017 compared to 2005 , i.e., a global reduction in $\eta_{N}$ by about $0.5-1 \%$. All data sets have the same emissions for 2015-2023, except the baseline. Hence results from MACv2-SP other than the baseline are identical with the two-yearblip results for this period (Fig. 5 and Table 1 ).

The post-pandemic recovery of $\tau_{a}$ and $\eta_{N}$ strongly depends on the scenario. The $\overline{\tau_{a}}$ in 2030 is close to the value in 2005 in the baseline and two-year-blip scenario, larger in the fossil fuel scenario, and substantially smaller for both green scenarios (Fig. 5). By 2050 all scenarios point to a decrease of $\overline{\tau_{a}}$ relative to 2005 , with the strongest reduction in the moderate green not the strong green scenario. This might be counter intuitive since a stronger green scenario might suggest cleaner air. The smaller $\overline{\tau_{a}}$ in the moderate green scenario is due to the lower emissions of $\mathrm{NH}_{3}$ compared to the strong green by about $-3.5 \times 10^{-6} \mathrm{~kg} \mathrm{~m}^{-2} \mathrm{~s}^{-1}$ in 2050, integrated over the globe and sectors. Although the emissions of $\mathrm{SO}_{2}$ are smaller in the strong green scenario, the total effect of $\mathrm{NH}_{3}$ and $\mathrm{SO}_{2}$ on the scaling factor $E_{i}$ (Section 2) leads to a slightly larger $\overline{\tau_{a}}$ in the strong green scenarios.

The assumption of larger $\mathrm{NH}_{3}$ emissions in the strong green recovery scenario compared to the moderate green recovery scenario is the result of changes in the structure of the economy in low emissions scenarios, particularly related to agricultural practice and energy provision. Stringent emissions scenarios to an increasing degree rely on more efficient food and biomass production to support a growing world

Table 1

Global means from the new MACv2-SP data and EC-Earth3 experiments. Shown are the ERF at the top of the atmosphere $\left(E R F_{T O A}\right)$ and at the surface $\left(E R F_{S F C}\right)$ calculated against $p i$ as the mean $\pm 95 \%$ confidence interval. (*) marks differences to the baseline that are statistically significant at the $95 \%$ level.

\begin{tabular}{lllll}
\hline Experiment & $\overline{\tau_{a}}$ & $\overline{\eta_{N}}$ & $E R F_{T O A}\left[\mathrm{Wm}^{-2}\right]$ & $E R F_{S F C}\left[\mathrm{Wm}^{-2}\right]$ \\
\hline 2020-base & 0.021 & 1.060 & $-0.661 \pm 0.087$ & $-1.449 \pm 0.047$ \\
2020-blp & 0.019 & 1.056 & $-0.622 \pm 0.072$ & $-1.338 \pm 0.038\left(^{*}\right)$ \\
2050-base & 0.019 & 1.054 & $-0.631 \pm 0.068$ & $-1.324 \pm 0.035$ \\
2050-ff & 0.020 & 1.057 & $-0.675 \pm 0.081$ & $-1.409 \pm 0.041\left(^{*}\right)$ \\
2050-mg & 0.012 & 1.038 & $-0.382 \pm 0.080\left(^{*}\right)$ & $-0.875 \pm 0.036\left(^{*}\right)$ \\
2050-sg & 0.014 & 1.040 & $-0.461 \pm 0.069\left(^{*}\right)$ & $-0.987 \pm 0.039\left(^{*}\right)$ \\
\hline
\end{tabular}
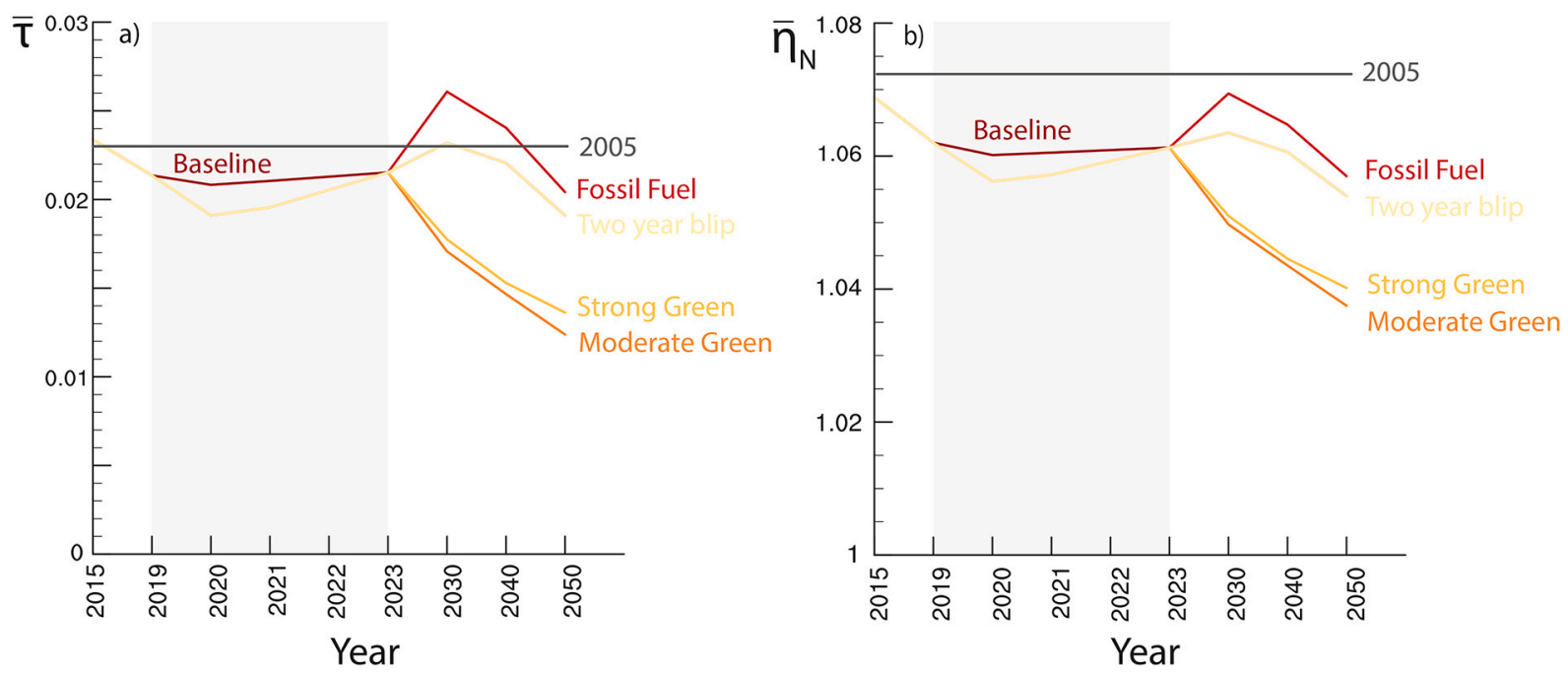

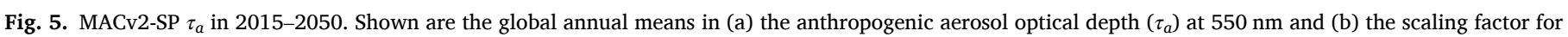

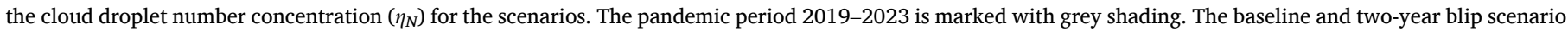
overlap for 2030-2050. All scenarios except baseline overlap for 2015-2030. The 2005 value from the historical scaling is marked as horizontal line. 
population while generating low-carbon energy and enable possibilities of carbon-dioxide sequestration (Popp et al., 2017). The fertilizer use required to achieve this results in an increase in $\mathrm{NH}_{3}$ emissions. Furthermore, stringent climate change mitigation scenarios often rely on very high shares of renewable energy, which have intermittent power generation properties and thus require energy storage technologies to bridge gaps in supply. One technology that can store energy across seasons and even multiple years is the production of ammonia (Society, 2020). The projected increased use of ammonia, as a fuel and for energy storage, results in larger projected emissions of $\mathrm{NH}_{3}$ due to leakage and due to imperfect transport or storage. Slightly higher $\mathrm{NH}_{3}$ emissions in the strong green $(s g)$ than the moderate $(m g)$ recovery scenarios are hence consistent with the general understanding of the technologies and practices that would be required for a transformation to a strongly decarbonized society.

\subsection{Hemispheric asymmetry in $\tau_{a}$}

The spatial distribution of $\tau_{a}$, measured by the hemispheric asymmetry, is qualitatively similar across the scenarios, but the magnitudes differ. Fig. 6 illustrates the hemispheric asymmetry $A$ :

$A=\frac{\overline{\tau_{a}(\varphi)}-\overline{\tau_{a}(-\varphi)}}{2}$

using the zonal averages $\tau_{a}(\varphi)$ at the same geographical latitudes on the northern $(\varphi)$ and southern hemisphere $(-\varphi)$. All scenarios have larger $A$ in the tropics and sub-tropics than further poleward (Fig. 6), consistent with the CMIP6 scenarios (Fiedler et al., 2019a). For 2030, the fossil fuel and baseline scenarios have substantially higher $A$ than for 2020. In the middle of the 21st century, $A$ in the fossil fuel and baseline scenarios are more similar to each other and close to $A$ from 2020, consistent with little differences in the spatial distribution of the emissions.

The temporal behaviour for $A$ in the green scenarios is different to the fossil-fuel dominated scenarios, i.e., they are close to $A$ from 2020 in 2030 , but both much lower in 2050. Both green scenarios in 2030 have particularly similar $A$ to 2020 in the tropics and slightly larger differences poleward. In 2050, the green scenarios are still similar to each other, but have overall smaller $A$ compared to 2020 , e.g., a reduction by $50 \%$ in the maximum around $\varphi=24^{\circ}$. This reflects the decrease in $\tau_{a}$ due to improved air quality in a green recovery (compare Fig. 5).

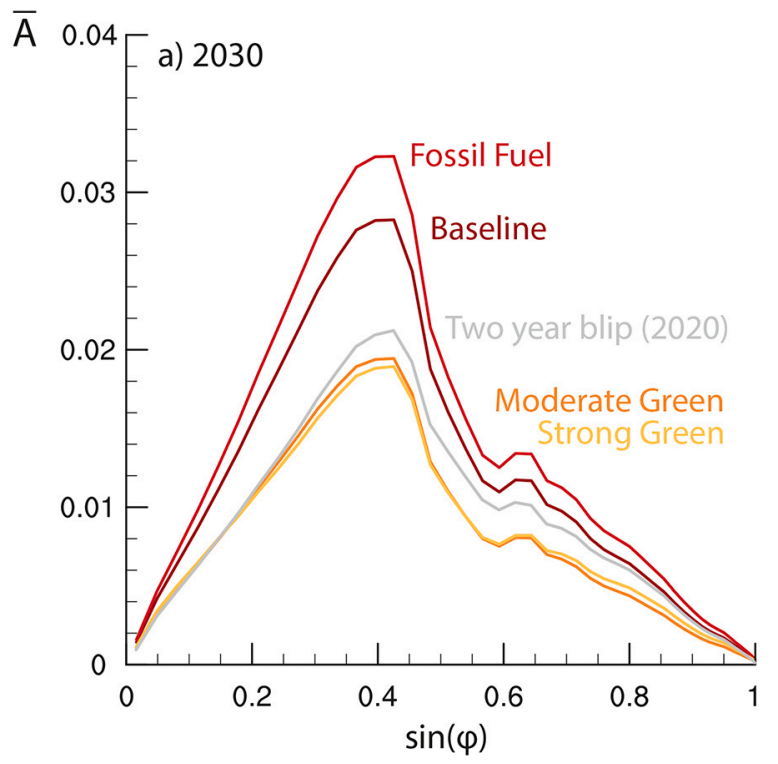

\subsection{Seasonal cycle in $\tau_{a}$}

The month-to-month changes in $\tau_{a}$ from MACv2-SP is dominated by the biomass burning seasons. These lead to tropical maxima in $\tau_{a}$ between July and October, and November and February (Fig. 7a-b). Overall, the seasonal and zonal patterns in the two-year-blip scenario and baseline are very similar (not shown). Note here again that all data sets are identical with the two-year-blip in 2020, except the baseline.

In 2050, the overall seasonal pattern in $\tau_{a}$ remains qualitatively similar, but the magnitudes strongly depend on the scenario. The fossil fuel and baseline scenario are very similar (not shown), but the green scenarios show large reductions in $\tau_{a}$ relative to baseline (Fig. 8a-c). These are primarily projected in the northern hemisphere equatorward of $50^{\circ} \mathrm{N}$. Here, the strongest reductions occur between June and October in the moderate green scenario. Again the stronger reduction in $\tau_{a}$ in the moderate than the strong green scenario is associated with the larger emissions of $\mathrm{NH}_{3}$ in the strong green recovery leading to larger $\tau_{a}$ than for the moderate green scenario.

\subsection{Global radiative forcing}

We calculate the global ERF of anthropogenic aerosols from our experiments with the new MACv2-SP data at the top of the atmosphere and at the surface, $E R F_{T O A}$ and $E R F_{S F C}$. For 2020, the impact of the reduction in anthropogenic aerosols compared to the baseline is a less negative $E R F_{T O A}$ by about $+0.04 \mathrm{Wm}^{-2}$ (Table 1 ). This reduction is small compared to the year-to-year variability in the model, reflected by the confidence intervals about the mean of $\pm 0.07 \mathrm{Wm}^{-2}$ to $\pm 0.09 \mathrm{Wm}^{-2}$ across our ensemble of model simulations. Again these estimates are based on fifty years of simulations with annually repeating aerosol patterns. It will therefore be difficult to disentangle any differences in the TOA radiation budget due to reductions in aerosols during the pandemic from differences arising due to natural variability in both observations and small ensembles of simulations. We identify a larger and statistically significant difference in $E R F_{S F C}$ associated with the aerosol reduction during the pandemic compared to the baseline of the order of $0.1 \mathrm{Wm}^{-2}$ (Table 1). This implies that radiation observations at the surface and sufficiently many model estimates for $E R F_{S F C}$ can be more informative for quantifying the influence of the pandemic on the global radiation and energy budget than estimates for the TOA.

The spread in $E R F_{T O A}$ of anthropogenic aerosols due to the different

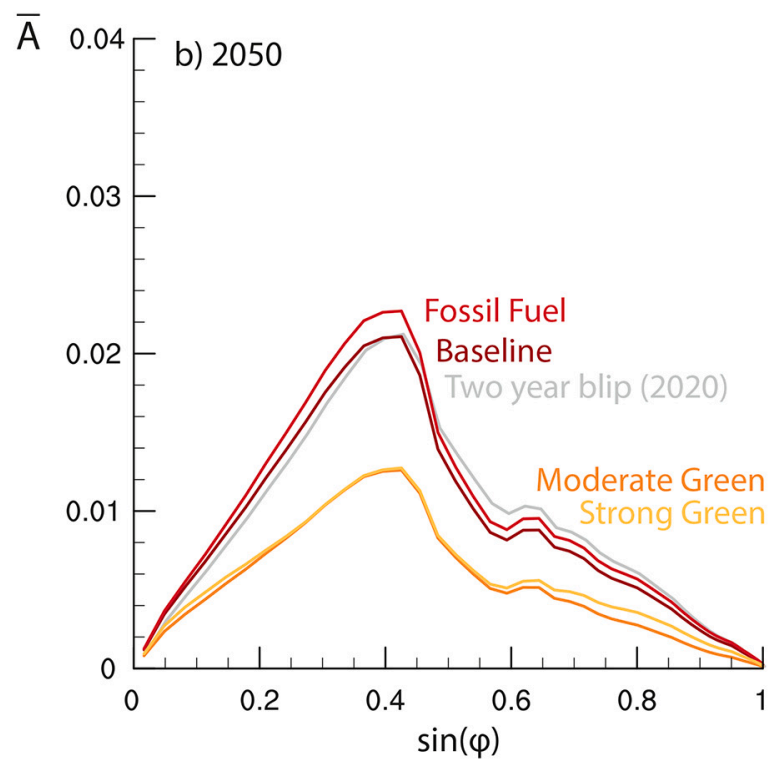

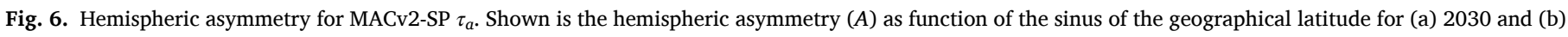
2050 for all scenarios. Baseline and two-year blip are identical for these years. We mark the values of the two-year blip scenario in 2020 as a reference. 

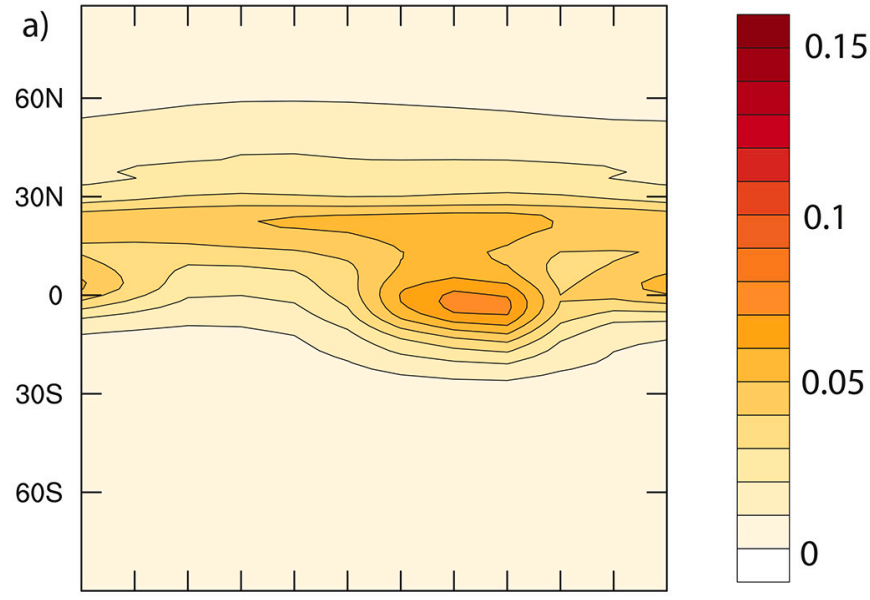

Jan Feb Mar Apr May Jun Jul Aug Sep Oct Nov Dec
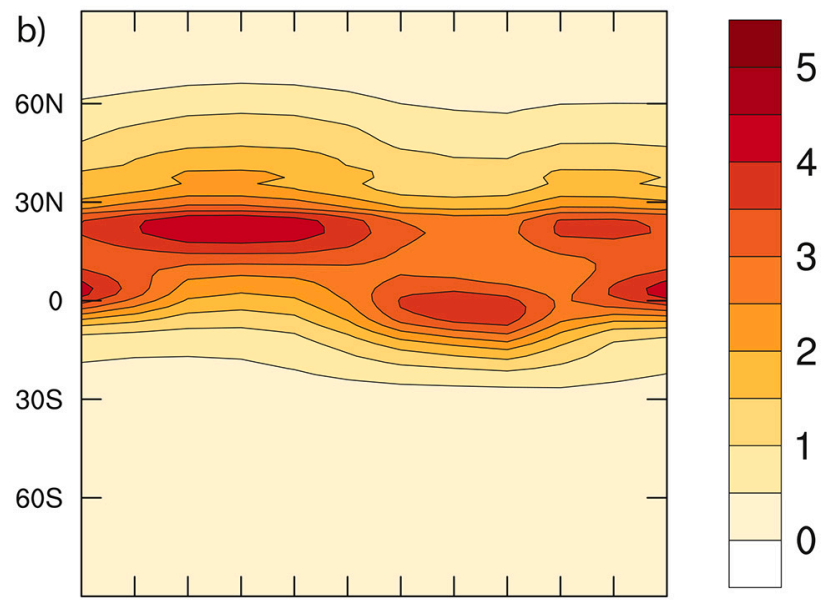

Jan Feb Mar Apr May Jun Jul Aug Sep Oct Nov Dec

Fig. 7. MACv2-SP $\tau_{a}$ patterns in 2020. Shown are the annual cycles of the anthropogenic aerosol optical depth $\left(\tau_{a}\right)$ at $550 \mathrm{~nm}$ as (a) zonal means and (b) zonal means weighted by $\overline{\tau_{a}}$ for the two-year-blip scenario.

scenarios for 2050 is $-0.68 \mathrm{Wm}^{-2}$ to $-0.38 \mathrm{Wm}^{-2}$ (Table 1 ). Compared to the baseline, these are differences of +0.05 to $-0.25 \mathrm{Wm}^{-2}$. The least negative $E R F_{T O A}$ occurs for the moderate green scenario, consistent with the lowest $\tau_{a}$ across the MACv2-SP data associated with the lower $\mathrm{NH}_{3}$ emissions than in the strong green scenario. We obtain $E R F_{T O A}$ of the anthropogenic aerosols for the green scenarios that are statistically significant different compared to the baseline. Baseline and the fossilfuel based scenarios, however, yield very similar $E R F_{T O A}$ for 2050, consistent with small differences in $\overline{\tau_{a}}$ and $\overline{\eta_{N}}$ for the two scenarios (Fig. 9a). The $E R F_{S F C}$ for 2050 is more negative than $E R F_{T O A}$ (Fig. 9b) and has a smaller $95 \%$ confidence interval of about $\pm 0.04 \mathrm{Wm}^{-2}$ compared to $E R F_{T O A}$. We therefore find for all scenarios a statistically significant difference in $E R F_{S F C}$ relative to 2050-base (Table 1).

\subsection{Pattern of radiative effects}

We assess the spatial distribution of the radiative effects associated with the anthropogenic aerosols. To this end, we calculate the effective radiative effects in all-sky $\left(F_{\text {all }}\right)$, clear-sky $\left(F_{c l r}\right)$, and cloudy-sky $\left(F_{c l d}\right)$ using the relationship:

$F_{\text {all }}=(1-f) F_{\text {clr }}+f F_{\text {cld }}$,

with the total cloud cover (f). Figs. 10 and 11 show the results for the top of the atmosphere (TOA) and at the surface.

For 2020, we find some evidence for regionally significant differences in the radiative effects at TOA associated with anthropogenic aerosol reductions due to the pandemic. We measure significance at the $95 \%$ confidence level. Significant regional signals at TOA are rare, and primarily limited to $F_{c l r}$ (Fig. 10). This is primarily explained by the strong variability of clouds. The difference in $F_{c l r}$ at TOA indicates less negative radiative effects over some regions, e.g., offshore of typically polluted regions in Asia. This is consistent with the expectation of a more negative aerosol radiative effect for a given aerosol plume over a dark ocean surface than over a relatively brighter land surface. Less aerosols during 2020 therefore coincide with a less negative radiative effect of anthropogenic aerosols over the ocean than over land, seen as positive anomaly in Fig. 10. At the surface, the regional differences in the described radiative effects are more pronounced and spatially further extended in $F_{c l r}$, covering large parts in Southeast Asia and East Asia both over land and ocean, and are also seen in $F_{\text {all }}$ for some regions (Fig. 10). Surface measurements in these regions could potentially help to constrain the aerosol effects on climate. Much of the radiative effects occur over oceans, where the measurement network is typically sparse. Efforts to collect necessary observations during this unique situation could involve sun photometer measurements aboard research vessels as part of the Maritime Aerosol Network (e.g., Smirnov et al., 2009) and in-situ measurements aboard aircrafts based on existing expertises (e.g., Zuidema et al., 2016).

The scenario differences in the radiative effects at TOA for 2050 are largest in South, Southeast and East Asia (Fig. 11). Here, $F_{c l r}$ shows significant differences with less negative radiative effects in the moderate green scenario compared to the baseline by up to $3 \mathrm{Wm}^{-2}$. This result is in agreement with the expectation of less aerosol scattering and absorption associated with the lower $\tau_{a}$. The pattern of $F_{c l d}$ is again more
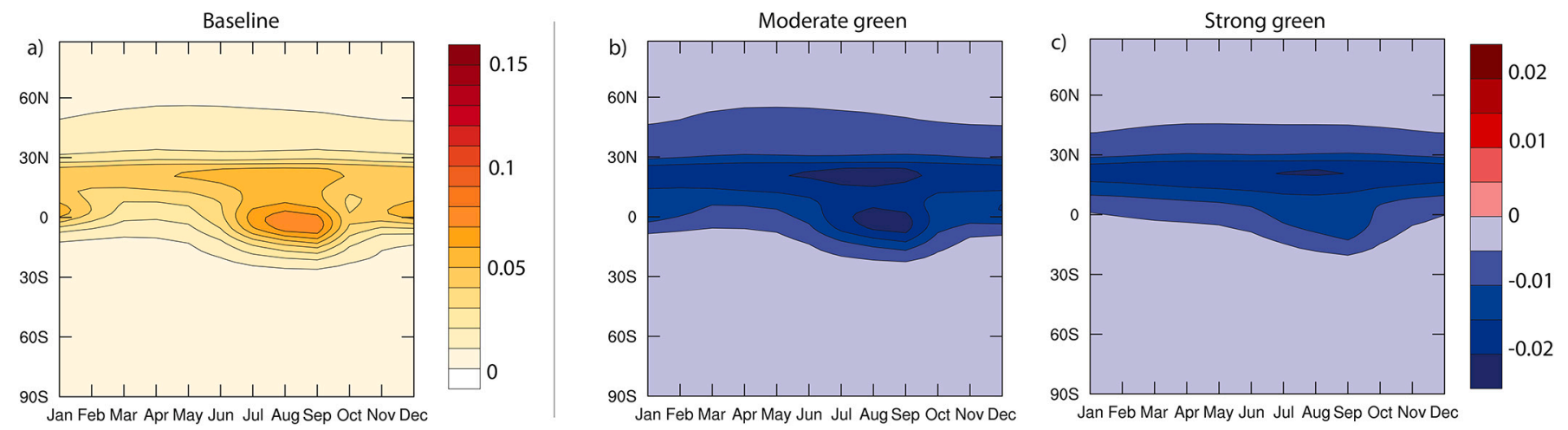

Fig. 8. MACv2-SP $\tau_{a}$ patterns in 2050. Shown is the annual cycles of the anthropogenic aerosol optical depth $\left(\tau_{a}\right)$ at $550 \mathrm{~nm}$ as (a) zonal mean for the baseline, and (b-c) difference of the green scenarios relative to baseline for 2050. 

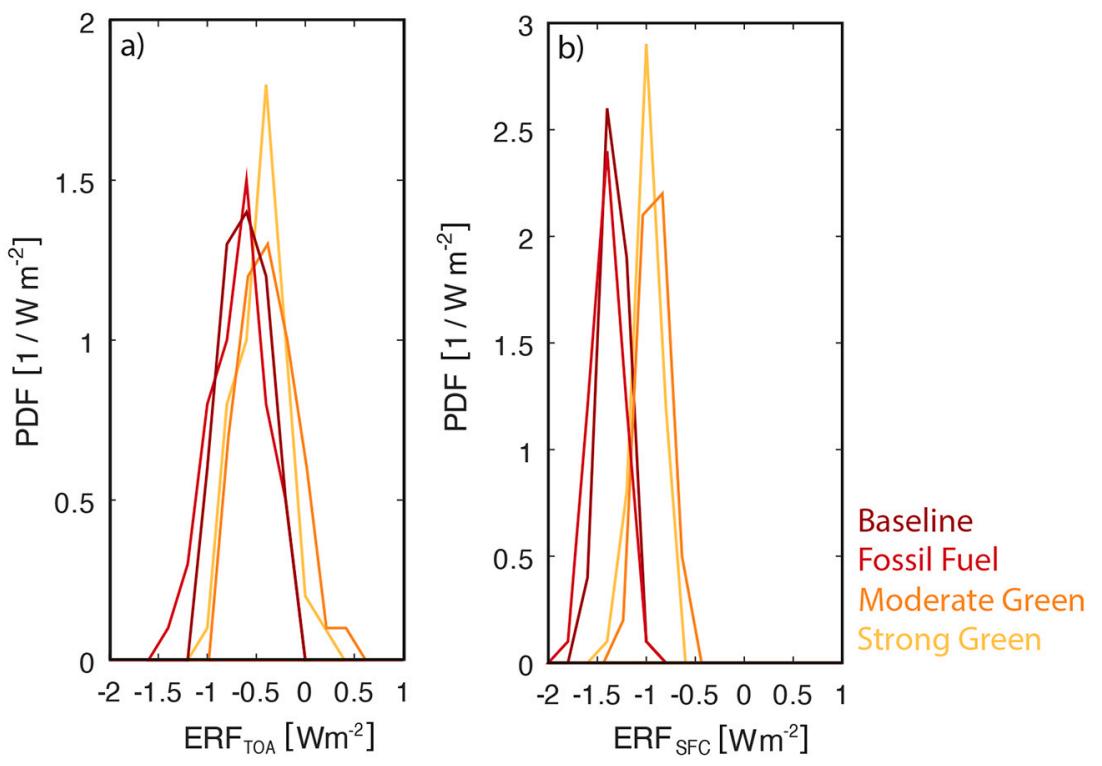

Fig. 9. Probability density function for the global mean ERF in 2050. Shown are the occurrence frequency of annual mean ERF at (a) the top of the atmosphere (TOA) and (b) the surface (SFC) for the color-coded scenarios in 2050. ERF is calculated from 50 years of data from our EC-Earth3 experiments with anthropogenic aerosols (2050-base, 2050-ff, 2050-mg, 2050-sg) against the pre-industrial control experiment (pi).
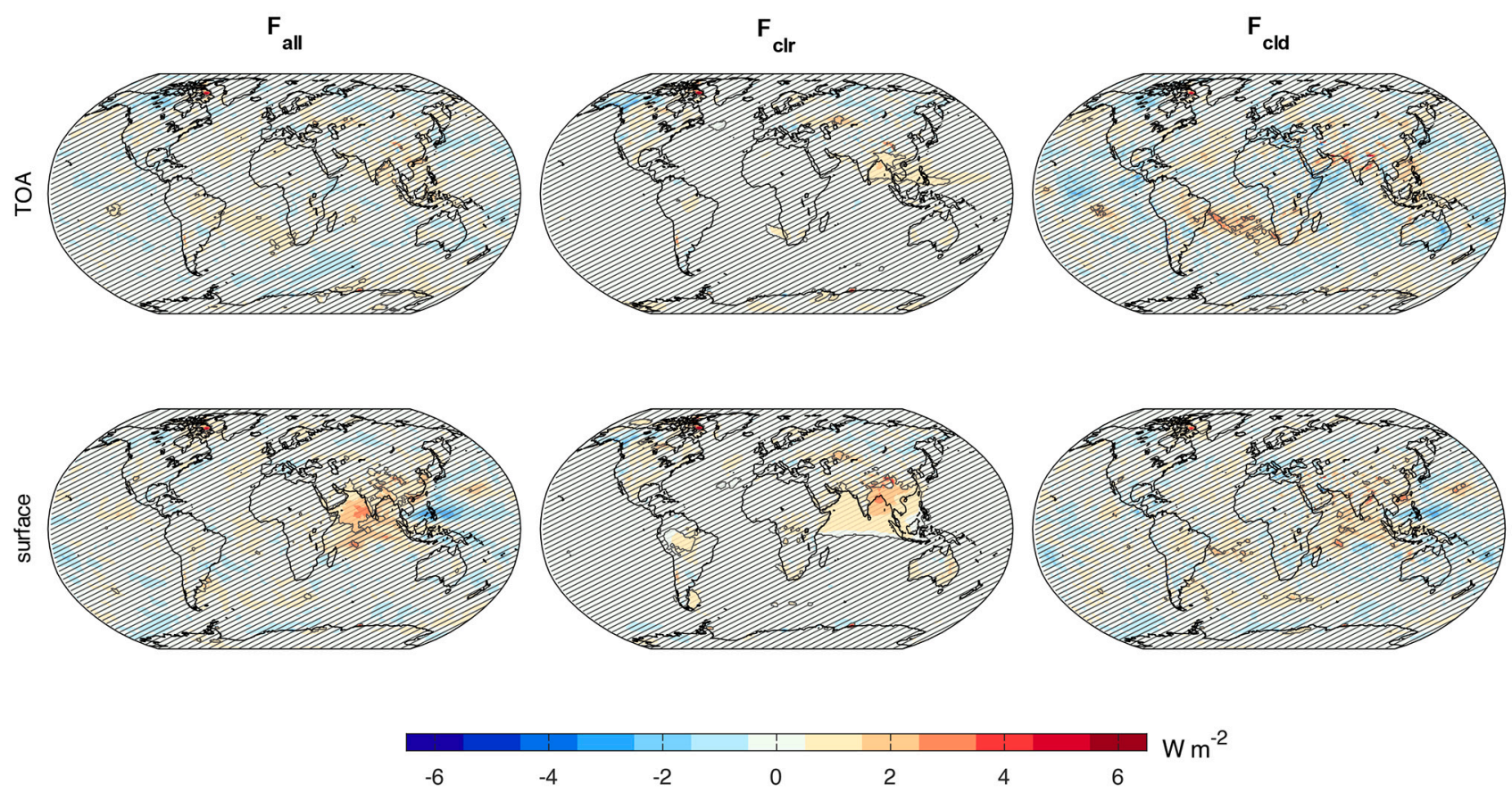

Fig. 10. Differences in effective radiative effects due to the pandemic in 2020. Shown are differences between 2020-blp and 2020-base for the effective radiative effects in (left) all-sky $\left(F_{\text {all }}\right)$, (middle) clear-sky $\left(F_{c l r}\right)$ and (right) cloudy-sky $\left(F_{c l d}\right)$ at (top) the top of the atmosphere and (bottom) the surface. Hatched areas mark regions where the differences are not statistically significant at the $95 \%$ confidence level.

inhomogeneous than $F_{c l r}$. Scenario differences for $F_{c l d}$ are again not significant for most world regions. The overall pattern for $F_{\text {all }}$ differences at the surface is qualitatively similar to TOA, but the magnitude and spatial extent of significant differences are larger at the surface. Based on these results, significant scenario differences for the radiative effects associated with anthropogenic aerosols are primarily confined to the tropics and sub-tropics close to hotspots for industrial and biomass burning activity at present.

\section{Discussion and conclusion}

We show the anthropogenic aerosol optical properties and the associated effect on clouds from MACv2-SP. The new MACv2-SP data is based on the COVID-19 emission data from Forster et al. (2020a) for use in CovidMIP (Jones et al., 2021; Lamboll et al., 2021)). Our results point to a reduction in the global anthropogenic aerosol optical depth by $10 \%$ due to the pandemic compared to the baseline. Scenarios for the post-pandemic recovery indicate a continuous increase in aerosols until 2030 in scenarios without more green technologies and a general 

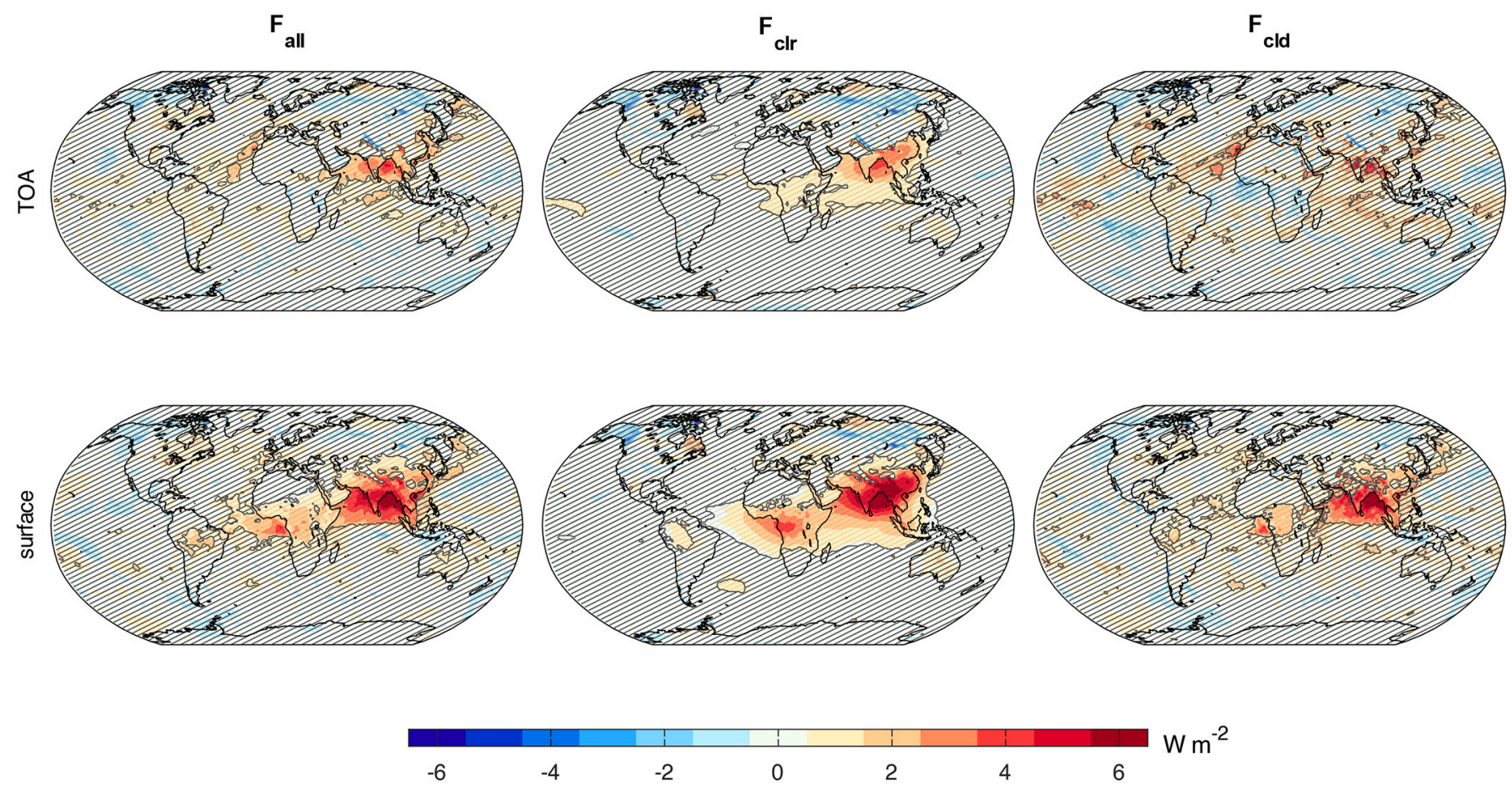

Fig. 11. As Fig. 10 but for the differences between the moderate green (2050-mg) against the baseline (2050-base) scenario in 2050.

decrease in all scenarios for 2030-2050. The spread in the anthropogenic aerosol optical depth in 2050 is 0.012 (medium green scenario) to 0.02 (fossil fuel scenario). These values fall within the lower end of the spread in 2050 obtained from the original CMIP6 aerosol scenarios (Fiedler et al., 2019b).

First estimates of the effective radiative forcing (ERF) associated with the new MACv2-SP data are calculated from several hundred years of atmosphere-only simulations with EC-Earth3. The results highlight a weaker (less negative) aerosol ERF of the order of $10 \%$ during the pandemic relative to the baseline. Such small ERF differences require long averaging, hence our 50 years of simulations for each aerosol pattern assessed here. The small change in aerosol ERF for the time of the pandemic is not expected to induce a global climate response that is clearly detectable in light of model-internal variability. Even regional radiative effects are rather difficult to detect at the top of the atmosphere. We find, however, more significant effective radiative effects at the surface in regions typically more strongly polluted by aerosols. Any attempt to use the pandemic period to constrain aerosol effects should therefore focus on areas in South and East Asia, primarily assessing radiative effects at the surface paired with a validation of the representation of observed regional emissions. This may involve station observations for radiation and aerosols, e.g., from aerosol networks (Xin et al., 2015; Giles et al., 2019). Our experiments suggest that aerosol radiative effects are expected offshore of land with major pollution in the past decades. We therefore propose to also use other measurements, e.g., from sun photometers aboard research vessels or in-situ instruments from aircrafts. Measurements outside of clouds might be particularly beneficial, although much research focuses on aerosol-cloud interactions. Our model results indeed suggest that there are better chances to obtain a signal in clear-sky conditions at the surface rather than in cloudy and all sky. We mostly find poor prospects to measure a meaningful regional effect on clouds due to the strong influence of natural variability.

For 2050, we obtain an ERF spread of -0.68 to $-0.38 \mathrm{Wm}^{-2}$ relative to the pre-industrial, which is less negative than the ERF from the same model for 2005 and 1975 (Fiedler et al., 2019a). These ERF estimates for 2050 fall within the ERF spread for 2095 associated with the emission pathways from CMIP6 and uncertainty in aerosol-cloud interactions (Fiedler et al., 2019b). Interestingly, the stronger green scenario does not yield the smallest anthropogenic aerosol optical depth and least negative forcing, but the moderate green recovery does. This is associated with a relative increase in $\mathrm{NH}_{3}$ emissions due to intense land-use paired with an energy system primarily relying on renewable sources. Such a pathway implies a slightly stronger warming due to weaker aerosol cooling in the strong green than the moderate green scenario. We expect, however, a stronger reduction in greenhouse gas emissions in the strong green pathway. Taken together the anthropogenic warming in the strong green scenario is therefore expected to be the weakest. Regionally, our simulations suggest the largest differences in the aerosol radiative effects across sub-tropical and tropical regions. An interesting, yet difficult question in this context is to what extent future changes in emissions, and the associated radiative forcing and climate response, are truly attributed to influences of the pandemic and how much of it would have occurred for other reasons, e.g., due to policy changes as measure for improving air quality and mitigating climate change.

Our global ERF estimates for the anthropogenic aerosols fall within the plausible range of the present-day aerosol ERF (Bellouin et al., 2020) underlining the still large uncertainty in our understanding of aerosol effects compared to our ability to estimate a change in ERF from different emission pathways from a complex model. We expect that models participating in CovidMIP will show diversity in their aerosol ERF owing to model-internal variability and model biases, even when they use the same emissions or MACv2-SP data (e.g., Fiedler et al., 2019a; Smith et al., 2020). For instance, Weber et al. (2020) point to the small signal compared to the noise in a complex aerosol-climate model simulation for spring 2020. Reasons for the model diversity in aerosol ERF include not only uncertainties in the aerosol parameterizations, but also the ability of the host model to accurately simulate important processes influencing the aerosol life cycle and therefore ERF, e.g., the representation of clouds, precipitation, and circulation. Future research should therefore also address the relative contributions from host model biases to the model diversity in ERF. 


\section{Author statement}

Stephanie Fiedler led the study and the writing of the manuscript. She created, analysed, and visualized the MACv2-SP data. Klaus Wyser performed the EC-Earth3 experiments, analysed the forcing in the model output, and created the associated figures. All authors contributed to the writing, reviewing and editing of the article.

\section{Data availability}

The MACv2-SP code and input data are freely accessible in the supplement of previous (Stevens et al., 2017; Fiedler et al., 2019a) and this article. The results from the EC-Earth3 simulations used in this study are available from Wyser (2020).

Processed MODIS satellite data for the aerosol optical depth was downloaded from the Giovanni online data system (MOD08_M3 v6.1, https://giovanni.gsfc.nasa.gov/, accessed 4 Jan 2021), developed and maintained by the NASA GES DISC. We also acknowledge the MODIS mission scientists and associated NASA personnel for the production of the data shown in this article.

\section{Declaration of Competing Interest}

The authors declare no conflict of interest.

\section{Acknowledgments}

SF acknowledges the funding from the German Research Foundation for the Collaborative Research Centre 1211 (ID: DFG 268236062, https ://sfb1211.uni-koeln.de) and from the German Federal Ministry for Transportation and Digital Infrastructure for the Hans-Ertel-Centre for Weather Research (ID: BMVI/DWD 4818DWDP5A, https://www.herz. uni-bonn.de) as well as resources of the Deutsches Klimarechenzentrum (DKRZ) granted by its Scientific Steering Committee (WLA) under project ID bb1198. KW and TvN received support from European Union's Horizon 2020 research and innovation programme under grant agreement No. 821205 (FORCeS). The EC-Earth3 simulations were performed on resources provided by the Swedish National Infrastructure for Computing (SNIC) at NSC. We thank the four anonymous reviewers for their comments and the editor for handling our manuscript.

\section{Appendix A. Supplementary data}

Supplementary data to this article can be found online at https://doi. org/10.1016/j.atmosres.2021.105866.

\section{References}

Abdul-Razzak, H., Ghan, S.J., 2000. A parameterization of aerosol activation: 2. Multiple aerosol types. J. Geophys. Res. Atmos. 105, 6837-6844. https://doi.org/10.1029/ 1999JD901161.

Acker, J.G., Leptoukh, G., 2007. Online Analysis Enhances Use of NASA Earth Science Data. https://giovanni.gsfc.nasa.gov.

Andrijevic, M., Schleussner, C.F., Gidden, M.J., McCollum, D.L., Rogelj, J., 2020. Covid19 recovery funds dwarf clean energy investment needs. Science 370, 298-300. https://doi.org/10.1126/science.abc9697.

Bellouin, N., Quaas, J., Gryspeerdt, E., Kinne, S., Stier, P., Watson-Parris, D., Boucher, O., Carslaw, K.S., Christensen, M., Daniau, A.L., Dufresne, J.L., Feingold, G., Fiedler, S., Forster, P., Gettelman, A., Haywood, J.M., Lohmann, U., Malavelle, F., Mauritsen, T., McCoy, D.T., Myhre, G., Mölmenstädt, J., Neubauer, D., Possner, A., Rugenstein, M., Sato, Y., Schulz, M., Schwartz, S.E., Sourdeval, O., Storelvmo, T., Toll, V., Winker, D., Stevens, B., 2020. Bounding global aerosol radiative forcing of climate change. Rev. Geophys. 58 https://doi.org/10.1029/2019RG000660 e2019RG000660.

Berman, J.D., Ebisu, K., 2020. Changes in US air pollution during the covid-19 pandemic. Sci. Total Environ. 739, 139864. https://doi.org/10.1016/j.scitotenv.2020.139864.

Broomandi, P., Karaca, F., Nikfal, A., Jahanbakhshi, A., Tamjidi, M., Kim, J.R., 2020 Impact of COVID-19 event on the air quality in Iran. Aerosol Air Qual. Res. 20, 1793-1804. https://doi.org/10.4209/aaqr.2020.05.0205.
Cherian, R., Quaas, J., 2020. Trends in AOD, clouds, and cloud radiative effects in satellite data and CMIP5 and CMIP6 model simulations over aerosol source regions. Geophys. Res. Lett. 47 https://doi.org/10.1029/2020GL087132 e2020GL087132.

Chu, B., Ma, Q., Liu, J., Ma, J., Zhang, P., Chen, T., Feng, Q., Wang, C., Yang, N., Ma, H., Ma, J., Russell, A.G., He, H., 2020. Air pollutant correlations in china: secondary air pollutant responses to nox and so2 control. Environ. Sci. Technol. Lett. 7, 695-700. https://doi.org/10.1021/acs.estlett.0c00403.

Döscher, R., Acosta, M., Alessandri, A., Anthoni, P., Arneth, A., Arsouze, T., Bergmann, T., Bernadello, R., Bousetta, S., Caron, L.P., Carver, G., Castrillo, M., Catalano, F., Cvijanovic, I., Davini, P., Dekker, E., Doblas-Reyes, F.J., Docquier, D., Echevarria, P., Fladrich, U., Fuentes-Franco, R., Gr"oger, M.v., Hardenberg, J., Hieronymus, J., Karami, M.P., Keskinen, J.P., Koenigk, T., Makkonen, R., Massonnet, F., Ménégoz, M., Miller, P.A., Moreno-Chamarro, E., Nieradzik, L., van Noije, T., Nolan, P., O'Donnell, D., Ollinaho, P., van den Oord, G., Ortega, P., Prims, O.T., Ramos, A., Reerink, T., Rousset, C., Ruprich-Robert, Y., Le Sager, P., Schmith, T., Schr"odner, R., Serva, F., Sicardi, V., Sloth Madsen, M., Smith, B., Tian, T., Tourigny, E., Uotila, P., Vancoppenolle, M., Wang, S., Wårlind, D., Willén, U., Wyser, K., Yang, S., Yepes-Arbós, X., Zhang, Q., 2021. The EC-Earth3 Earth system model for the climate model intercomparison project 6. Geosci. Model Dev. Discuss. 2021, 1-90. https://doi.org/10.5194/gmd-2020-446.

ECMWF, 2010a. IFS DOCUMENTATION - Cy36r1 Operational Implementation 26 January 2010, PART III: DYNAMICS AND NUMERICAL PROCEDURES. European Center for Medium Range Weather Forecasts. In: www.ecmwf.int/sites/default/fi les/elibrary/2010/9232-part-iii-dynamics-and-numerical-procedures.pdf.

ECMWF, 2010b. IFS DOCUMENTATION - Cy36r1 Operational Implementation 26 January 2010, PART IV: PHYSICAL PROCESSES. European Center for Medium Range Weather Forecasts. In: www.ecmwf.int/sites/default/files/elibrary/2010/92 33-part-iv-physical-processes.pdf.

Eyring, V., Bony, S., Meehl, G.A., Senior, C.A., Stevens, B., Stouffer, R.J., Taylor, K.E., 2016. Overview of the coupled model intercomparison project phase 6 (CMIP6) experimental design and organization. Geosci. Model Dev. 9, 1937-1958. https:// doi.org/10.5194/gmd-9-1937-2016.

Fiedler, S., Kinne, S., Huang, W.T.K., R\&rdquo;ais\&ldquo;anen, P., O’Donnell, D., Bellouin, N., Stier, P., Merikanto, J., van Noije, T., Carslaw, K., Makkonen, R., Lohmann, U., 2019a. Anthropogenic aerosol forcing - insights from multi-estimates from aerosol-climate models with reduced complexity. Atmos. Chem. Phys. 19, 6821-6841. https://doi.org/10.5194/acp-19-6821-2019.

Fiedler, S., Stevens, B., Gidden, M., Smith, S.J., Riahi, K., van Vuuren, D., 2019b. First forcing estimates from the future CMIP6 scenarios of anthropogenic aerosol optical properties and an associated Twomey effect. Geosci. Model Dev. 12, 989-1007. https://doi.org/10.5194/gmd-12-989-2019.

Fiedler, S., Stevens, B., Mauritsen, T., 2017. On the sensitivity of anthropogenic aerosol forcing to model-internal variability and parameterizing a Twomey effect. J. Adv. Model. Earth Syst. 9 https://doi.org/10.1002/2017MS000932 n/a-n/a.

Forster, P.M., Forster, H.I., Evans, M.J., Gidden, M.J., Jones, C.D., Keller, C.A., Lamboll, R.D., Quéré, C.L., Rogelj, J., Rosen, D., Schleussner, C.F., Richardson, T.B., Smith, C.J., Turnock, S.T., 2020a. Current and future global climate impacts resulting from covid-19. Nat. Climate Change. https://doi.org/10.1038/s41558-0200883-0.

Forster, P.M., Lamboll, R., Rogelj, J., 2020b. Emissions Changes in 2020 Due to Covid19. https://doi.org/10.5281/zenodo.3957826.

Gettelman, A., Lamboll, R., Bardeen, C.G., Forster, P.M., Watson-Parris, D., 2020. Climate impacts of COVID-19 induced emission changes. Geophys. Res. Lett. https:// doi.org/10.1029/2020GL091805 e2020GL091805.e2020GL091805 2020GL091805.

Giles, D.M., Sinyuk, A., Sorokin, M.G., Schafer, J.S., Smirnov, A., Slutsker, I., Eck, T.F., Holben, B.N., Lewis, J.R., Campbell, J.R., Welton, E.J., Korkin, S.V., Lyapustin, A.I., 2019. Advancements in the aerosol robotic network (AERONET) version 3 database - automated near-real-time quality control algorithm with improved cloud screening for Sun photometer aerosol optical depth (AOD) measurements. Atmos. Meas. Tech. 12, 169-209. https://doi.org/10.5194/amt-12-169-2019.

Gillett, N.P., Shiogama, H., Funke, B., Hegerl, G., Knutti, R., Matthes, K., Santer, B.D., Stone, D., Tebaldi, C., 2016. The detection and attribution model intercomparison project (DAMIP v1.0) contribution to CMIP6. Geosci. Model Dev. 9, 3685-3697. https://doi.org/10.5194/gmd-9-3685-2016.

van Heerwaarden, C.C., Mol, W.B., Veerman, M.A., Benedict, I., Heusinkveld, B.G., Knap, W.H., Kazadzis, S., Kouremeti, N., Fiedler, S., 2021. Record high solar irradiance in Western Europe during first covid-19 lockdown largely due to unusual weather. Commun. Earth Environ. 2, 37. https://doi.org/10.1038/s43247-02100110-0.

Huppmann, D., Rogelj, J., Kriegler, E., Krey, V., Riahi, K., 2018. A new scenario resource for integrated $1.5^{\circ} \mathrm{C}$ research. Nat. Climate Change 8, 1027-1030. https://doi.org/ 10.1038/s41558-018-0317-4.

IPCC, 2021. Annex II: Models. In: Gutiérrez, J.M., Treguier, A-M. (Eds.), Climate Change 2021: The Physical Science Basis. Contribution of Working Group I to the Sixth Assessment Report of the Intergovernmental Panel on Climate Change [MassonDelmotte, V., P. Zhai, A. Pirani, S.L. Connors, C. Péan, S. Berger, N. Caud, Y. Chen, L. Goldfarb, M.I. Gomis, M. Huang, K. Leitzell, E. Lonnoy, J.B.R. Matthews, T.K. Maycock, T. Waterfield, O. Yelekçi, R. Yu and B. Zhou (eds.)]. Cambridge University Press (in press).

Jones, C.D., Hickman, J.E., Rumbold, S.T., Walton, J., Lamboll, R.D., Skeie, R.B., Fiedler, S., Forster, P.M., Rogelj, J., Abe, M., Botzet, M., Calvin, K., Cassou, C., Cole, J.N., Davini, P., Deushi, M., Dix, M., Fyfe, J.C., Gillett, N.P., Ilyina, T., Kawamiya, M., Kelley, M., Kharin, S., Koshiro, T., Li, H., Mackallah, C., Möller, W.A., Nabat, P., van Noije, T., Nolan, P., Ohgaito, R., Olivié, D., Oshima, N., Parodi, J., Reerink, T.J., Ren, L., Romanou, A., Séférian, R., Tang, Y., Timmreck, C., Tjiputra, J., 
Tourigny, E., Tsigaridis, K., Wang, H., Wu, M., Wyser, K., Yang, S., Yang, Y., Ziehn, T., 2021. The climate response to emissions reductions due to COVID-19: initial results from CovidMIP. Geophys. Res. Lett. 48 https://doi.org/10.1029/ 2020GL091883 e2020GL091883.

Lamboll, R.D., Jones, C.D., Skeie, R.B., Fiedler, S., Samset, B.H., Gillett, N.P., Rogelj, J., Forster, P.M., 2021. Modifying emissions scenario projections to account for the effects of covid-19: protocol for covidmip. Geosci. Model Dev. 14, 3683-3695. https://doi.org/10.5194/gmd-14-3683-2021. https://gmd.copernicus.org/artic les/14/3683/2021/.

Lamboll, R.D., Nicholls, Z.R.J., Kikstra, J.S., Meinshausen, M., Rogelj, J., 2020b. Silicone v1.0.0: An Open-Source Python Package for Inferring Missing Emissions Data for Climate Change Research, pp. 1-23. https://doi.org/10.5194/gmd-2020-138.

Madec, G., the NEMO team, 2016. NEMO Ocean Engine. Note du Pôle de modélisation. Institut Pierre-Simon Laplace (IPSL), France. No 27, ISSN No 1288-1619.

Mauritsen, T., Bader, J., Becker, T., Behrens, J., Bittner, M., Brokopf, R., Brovkin, V., Claussen, M., Crueger, T., Esch, M., Fast, I., Fiedler, S., Fl\&rdquo;aschner, D., Gayler, V., Giorgetta, M., Goll, D.S., Haak, H., Hagemann, S., Hedemann, C., Hohenegger, C., Ilyina, T., Jahns, T., Jimenez de la Cuesta Otero, D., Jungclaus, J., Kleinen, T., Kloster, S., Kracher, D., Kinne, S., Kleberg, D., Lasslop, G., Kornblueh, L. Marotzke, J., Matei, D., Meraner, K., Mikolajewicz, U., Modali, K., M\&ldquo;obis, B., M\&rdquo;uller, W.A., Nabel, J.E.M.S., Nam, C.C.W., Notz, D., Nyawira, S.S., Paulsen, H., Peters, K., Pincus, R., Pohlmann, H., Pongratz, J., Popp, M., Raddatz, T., Rast, S., Redler, R., Reick, C.H., Rohrschneider, T., Schemann, V., Schmidt, H., Schnur, R., Schulzweida, U., Six, K.D., Stein, L., Stemmler, I., Stevens, B., von Storch, J.S., Tian, F., Voigt, A., de Vrese, P., Wieners, K.H., Wilkenskjeld, S., Winkler, A., Roeckner, E., 2019. Developments in the MPI-M Earth system model version 1.2 (MPI-ESM 1.2) and its response to increasing CO2. J. Adv. Model. Earth Syst. 11, 998-1038. https://doi.org/10.1029/2018MS001400.

van Noije, T., Bergman, T., Le Sager, P., O’Donnell, D., Makkonen, R., GonçalvesAgeitos, M., D\&ldquo;oscher, R., Fladrich, U., von Hardenberg, J., Keskinen, J.P., Korhonen, H., Laakso, A., Myriokefalitakis, S., Ollinaho, P., Pérez García-Pando, C., Reerink, T., Schr\&rdquo;odner, R., Wyser, K., Yang, S., 2021. EC-Earth3-AerChem, a global climate model with interactive aerosols and atmospheric chemistry participating in CMIP6. Geosci. Model Dev. Discuss. Accept. 1-46. https://doi.org/ 10.5194/gmd-2020-413.

Pincus, R., Forster, P.M., Stevens, B., 2016. The radiative forcing model intercomparison project (RFMIP): experimental protocol for CMIP6. Geosci. Model Dev. 9, 3447-3460. https://doi.org/10.5194/gmd-9-3447-2016.

Platnick, S., Hubanks, P., Meyer, K., King, M.D., 2015. MODIS Atmosphere L3 Monthly Product (08_L3). NASA MODIS Adaptive Processing System. Goddard Space Flight Center. https://doi.org/10.5067/MODIS/MOD08_M3.006 (Terra), (Aqua).

Popp, A., Calvin, K., Fujimori, S., Havlik, P., Humpenöder, F., Stehfest, E., Bodirsky, B.L., Dietrich, J.P., Doelmann, J.C., Gusti, M., Hasegawa, T., Kyle, P., Obersteiner, M., Tabeau, A., Takahashi, K., Valin, H., Waldhoff, S., Weindl, I., Wise, M., Kriegler, E., Lotze-Campen, H., Fricko, O., Riahi, K., Vuuren, D.P.v., 2017. Land-use futures in the shared socio-economic pathways. Global Environ. Change 42, 331-345. https://doi. org/10.1016/j.gloenvcha.2016.10.002.

Ranjan, A.K., Patra, A.K., Gorai, A.K., 2020. Effect of lockdown due to sars covid-19 on aerosol optical depth (aod) over urban and mining regions in India. Sci. Total Environ. 745 https://doi.org/10.1016/j.scitotenv.2020.141024, 141024-141024.

Riemer, N., Doherty, O.M., Hameed, S., 2021. On the Variability of African Dust Transport Across the Atlantic.

Rogelj, J., Shindell, D., Jiang, K., Fifita, S., Forster, P., Ginzburg, V., Handa, C., Kheshgi, H., Kobayashi, S., Kriegler, E., Mundaca, L., Seferian, R., Vilarino, M.V., 2018. Mitigation Pathways Compatible With $1.5^{\circ} \mathrm{C}$ in the Context of Sustainable Development. IPCC/WMO, pp. 93-174. http://www.ipcc.ch/report/sr15/.

Sanap, S., 2021. Global and regional variations in aerosol loading during COVID-19 imposed lockdown. Atmos. Environ. 246, 118132. https://doi.org/10.1016/j. atmosenv.2020.118132.

Smirnov, A., Holben, B.N., Slutsker, I., Giles, D.M., McClain, C.R., Eck, T.F., Sakerin, S. M., Macke, A., Croot, P., Zibordi, G., Quinn, P.K., Sciare, J., Kinne, S., Harvey, M.,
Smyth, T.J., Piketh, S., Zielinski, T., Proshutinsky, A., Goes, J.I., Nelson, N.B., Larouche, P., Radionov, V.F., Goloub, P., Krishna Moorthy, K., Matarrese, R., Robertson, E.J., Jourdin, F., 2009. Maritime aerosol network as a component of aerosol robotic network. J. Geophys. Res. Atmos. 114 https://doi.org/10.1029/ 2008JD011257.

Smith, C.J., Kramer, R.J., Myhre, G., Alterskjær, K., Collins, W., Sima, A., Boucher, O., Dufresne, J.L., Nabat, P., Michou, M., Yukimoto, S., Cole, J., Paynter, D., Shiogama, H., O'Connor, F.M., Robertson, E., Wiltshire, A., Andrews, T., Hannay, C., Miller, R., Nazarenko, L., Kirkevåg, A., Olivié, D., Fiedler, S., Lewinschal, A., Mackallah, C., Dix, M., Pincus, R., Forster, P.M., 2020. Effective radiative forcing and adjustments in cmip6 models. Atmos. Chem. Phys. 20, 9591-9618. https://doi.org/ 10.5194/acp-20-9591-2020.

Society, T.R., 2020. Ammonia: Zero-Carbon Fertiliser, Fuel and Energy Store, 978-178252-448-9. https://royalsociety.org/-/media/policy/projects/green-ammonia/ green-ammonia-policy-briefing.pdf.

Song, Q., Zhang, Z., Yu, H., Ginoux, P., Shen, J., 2021. Global dust optical depth climatology derived from caliop and modis aerosol retrievals on decadal time scales: regional and interannual variability. Atmos. Chem. Phys. Discuss. 2021, 1-57. https://doi.org/10.5194/acp-2021-1.

Srivastava, A.K., Bhoyar, P.D., Kanawade, V.P., Devara, P.C., Thomas, A., Soni, V.K., 2021. Improved air quality during COVID-19 at an urban megacity over the IndoGangetic Basin: from stringent to relaxed lockdown phases. Urban Climate 36, 100791. https://doi.org/10.1016/j.uclim.2021.100791. https://www.sciencedirect. com/science/article/pii/S2212095521000213.

Stevens, B., Fiedler, S., Kinne, S., Peters, K., Rast, S., M\&ldquo;usse, J., Smith, S.J., Mauritsen, T., 2017. MACv2-SP: a parameterization of anthropogenic aerosol optical properties and an associated Twomey effect for use in CMIP6. Geosci. Mod. Dev. 10, 433-452. https://doi.org/10.5194/gmd-10-433-2017.

Sun, W., Shao, M., Granier, C., Liu, Y., Ye, C.S., Zheng, J.Y., 2018. Long-Term trends of anthropogenic SO2, NOx, CO, and NMVOCs emissions in China. Earth's Future 6, 1112-1133. https://doi.org/10.1029/2018EF000822.

Weber, J., Shin, Y.M., Staunton Sykes, J., Archer-Nicholls, S., Abraham, N.L., Archibald, A.T., 2020. Minimal climate impacts from short-lived climate forcers following emission reductions related to the COVID-19 pandemic. Geophys. Res. Lett. 47 https://doi.org/10.1029/2020GL090326 e2020GL090326.

Wyser, K., 2020. Effective Radiative Forcing (ERF) Experiments With EC-Earth3. https:// doi.org/10.5281/zenodo.4106258.

Wyser, K., Kjellstr\&rdquo;om, E., Koenigk, T., Martins, H., Döscher, R., 2020. Warmer climate projections in EC-Earth3-Veg: the role of changes in the greenhouse gas concentrations from CMIP5 to CMIP6. Environ. Res. Lett. 15, 054020.

Xin, J., Wang, Y., Pan, Y., Ji, D., Liu, Z., Wen, T., Wang, Y., Li, X., Sun, Y., Sun, J., Wang, P., Wang, G., Wang, X., Cong, Z., Song, T., Hu, B., Wang, L., Tang, G., Gao, W., Guo, Y., Miao, H., Tian, S., Wang, L., 2015. The campaign on atmospheric aerosol research network of China: CARE-China. Bull. Am. Meteorol. Soc. 96, 1137-1155. https://doi.org/10.1175/BAMS-D-14-00039.1.

Yamazaki, D., de Almeida, G.A.M., Bates, P.D., 2013. Improving computational efficiency in global river models by implementing the local inertial flow equation and a vector-based river network map. Water Resour. Res. 49, 7221-7235. https:// doi.org/10.1002/wrcr.20552.

Yang, Y., Ren, L., Li, H., Wang, H., Wang, P., Chen, L., Yue, X., Liao, H., 2020. Fast climate responses to aerosol emission reductions during the COVID-19 pandemic. Geophys. Res. Lett. 47 https://doi.org/10.1029/2020GL089788 e2020GL089788.

Zhang, M., Katiyar, A., Zhu, S., Shen, J., Xia, M., Ma, J., Kota, S.H., Wang, P., Zhang, H., 2021. Impact of reduced anthropogenic emissions during COVID-19 on air quality in India. Atmos. Chem. Phys. 21, 4025-4037. https://doi.org/10.5194/acp-21-40252021. https://acp.copernicus.org/articles/21/4025/2021/.

Zuidema, P., Redemann, J., Haywood, J., Wood, R., Piketh, S., Hipondoka, M., Formenti, P., 2016. Smoke and clouds above the Southeast Atlantic: upcoming field campaigns probe absorbing aerosol's impact on climate. Bull. Am. Meteorol. Soc. 97, 1131-1135. https://doi.org/10.1175/BAMS-D-15-00082.1. 